\title{
Designing forest landscape management
}

\author{
by Emin Z. Baskent ${ }^{1}$, Glen A. Jordan² and A.M.M. Nurullah ${ }^{3}$
}

Contemporary forest management design is generating innovative ideas as it evolves towards the management of forest landscapes. These ideas embody different management paradigms, modelling approaches and software engineering techniques. We explore these three in detail and suggest an ecological landscape management (ELM) paradigm coupled with meta-heuristics modelling and object-oriented software engineering techniques as a suitable framework for designing management for forest landscapes. We hope the paper provides insight and stimulates discussion about various forest landscape management design approaches.

Key words: forest landscape management, forest modelling, software engineering

La conception actuelle de l'aménagement forestier génère de nouvelles idées à mesure qu'elle évolue vers l'aménagement des paysages forestiers. Ces idées comportent différents paradigmes d'aménagement, différentes approches de modélisation et plusieurs techniques d'ingénierie de logiciels. Nous explorons ces trois éléments en détail et nous suggérons un paradigme d'aménagement écologique des paysages associé à des techniques meta-heuristiques de modélisation et d'ingénierie des logiciels orientées sur l'objet en tant que cadre de travail pour la conception de l'aménagement des paysages forestiers. Nous souhaitons que cet article ouvre des possibilités et stimule des discussions sur les différentes approches de conception de l'aménagement des paysages.

Mots-clés: aménagement des paysages forestiers, modélisation forestière, ingénierie des logiciels

\section{Introduction}

Today, there is little disagreement that forest management around the world in general, and across North America in particular, is evolving rapidly. The change has been quite obvious in new forest management paradigms as well as design and implementation of management interventions. Growing public pressure and international market access restrictions challenged us to sustainably manage forests for multiple values such as timber, water quality, wildlife habitat and biodiversity. As an immediate solution, many jurisdictions across Canada and the United States have adopted regulations that seek to maintain some of the non-timber values by increasing restrictions on industrial timber operations. Although these regulations have improved the environmental image of governments, they have increased conflicts between industry and environmental groups pressing for further austerity in timber operations (Kimmins 1993).

Eventually, forest scientists and professionals began to realize that a more holistic approach was needed. Mere regulatory constraints on timber operations, without considering longterm forest dynamics, are unlikely to sustain multiple values. This thinking resulted in large-scale initiatives by the governments of Canada and the United States in the early 1990s under the auspices of Sustainable Forest Management and Ecosystem Management, respectively (Brooks and Grant 1992). These initiatives

${ }^{1}$ Associate Professor., Karadeniz Technical University Faculty of Forestry, 61080 Trabzon, Turkey. E-mail: eminzeki@mailcity.com. Currently a visiting researcher at the Faculty of Forestry and Environmental Management, University of New Brunswick, PO Box 44555, Fredericton, NB E3B 6C2. E-mail: baskent@unb.ca

${ }^{2}$ Corresponding author, Professor, Faculty of Forestry and Environmental Management, University of New Brunswick, PO Box 44555, Fredericton, NB E3B 6C2. E-mail: jordan@unb.ca

${ }^{3} \mathrm{Ph} . \mathrm{D}$. candidate, Faculty of Forestry and Environmental Management, University of New Brunswick, PO Box 44555, Fredericton, NB E3B 6C2.

E-mail: i5ch@unb.ca

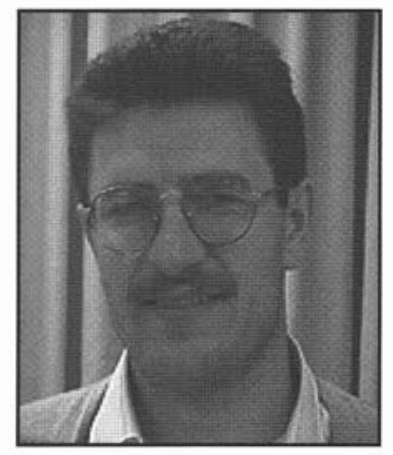

Emin Baskent

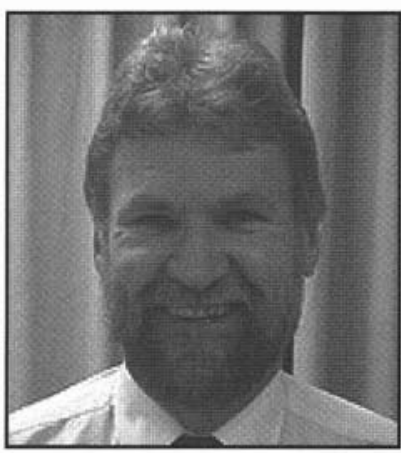

Glen Jordan fostered the evolution of forest management with the development of ecosystem-based, forest landscape management. Essentially, forest landscape management works on the premise that a sustainable flow of various resource values can be achieved by managing forests as ecosystems (Baskerville 1997). It emphasizes controlling spatial structure, i.e., composition and configuration of forest conditions, by orches-

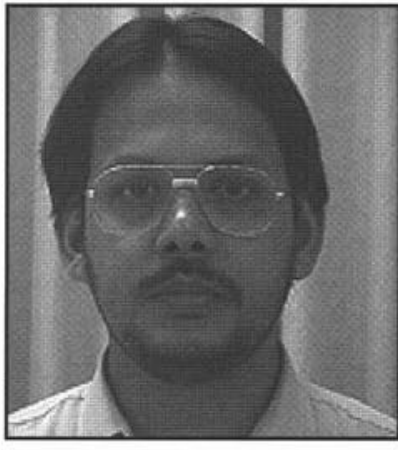

A.M.M. Nurullah trating management interventions (Baskent and Jordan 1995). As such, it embodies two challenges: first, defining and translating diverse social and ecological values into specific spatial structure objectives, and second, designing management to achieve those objectives.

Over the past few years, relationships between spatial structure and various resource values have been established. There is an apparent lack of similar accomplishment, however, in identifying an effective framework for forest landscape manage- 
ment design. In this paper we present and discuss a design framework consisting of three interrelated components: (i) a management paradigm; (ii) a modelling approach; and, (iii) a software engineering technique.

\section{Management Paradigms}

We define a forest management paradigm as a belief system one would adopt to design and implement forest management. It might be viewed as a "sketch board" for establishing management objectives and laying out a decision-making process. Currently, we can distinguish at least three different management paradigms - integrated resource management, forest zoning management, and natural disturbance model management. These three are distinguished primarily by their position along the continuum of integrated to segregated forest management.

Integrated resource management (IRM) is the traditional paradigm. It has a commodity focus and advocates the use of each forest hectare simultaneously for different values such as timber, fuel wood and wildlife habitat (Oliver 1999). In reality, however, this approach has lived more in theory than in practice due to our inability, or unwillingness, to deal with the complexity of designing management that sustains multiple resource values from the same piece of forest.

At the other end of the forest management continuum, we find the forest zoning paradigm, including the Triad Approach (Seymour and Hunter 1992) and its derivative, the Forestland Allocation Strategy (FAS) by Binkley (1997). In both, a forest landscape is segregated into three land use classes, or zones - intensive timber management areas, ecological reserve areas, and so-called new forestry areas. Intensive timber management areas are used to maximize commodity production by exploiting the easily accessible and the most productive parts of the forest landscape. Ecological reserve areas, on the other hand, permanently exclude human disturbances. The remaining new forestry areas are reserved for management interventions that mimic natural disturbance processes, while producing limited commodity values. The premise of forest zoning is that focusing silvicultural research and capital investment in the intensive management areas will offset losses in the other areas (Binkley 1997).

The forest zoning paradigm has received a lot of attention and endorsements from environmentalists, but provides little flexibility in designing forest landscape management for a number of reasons. First, permanent forest zoning ignores a fundamental reality - most resource values are widely distributed spatially over a forest landscape (Franklin 1998). For example, water quality cannot be maintained by setting aside and isolating one part of a watershed. The same can be said for many wildlife habitats, where species require large tracts of forest in large contiguous patches. Second, intensifying management in certain areas will require additional cost and increase uncertainty. It is uncertain, for example, whether areas zoned for intensive management can maintain a high state of productivity over long time periods. Third, land tenure systems, as well as social, cultural and spiritual values, may circumvent the desired forest landscape zoning (Sherry and Johnston 1999).

Another management paradigm, the natural disturbance model (NDM), has also recently appeared in places across North America. Examples can be found in the Pacific Northwest of the United States and in Ontario and Alberta in Canada.
Unlike forest zoning management, the NDM is based on the principle of ecological sustainability and is focused on maintaining the full range of forest ecosystems with a continuum of resource values interspersed across the landscape at varying levels (Booth et al. 1993). The primary objective in the NDM is mimicking the intensity, severity and frequency of natural disturbances, such as fire (Bergeron et al. 1999), since it is believed that the diversity, structure and ecological processes of forests are moulded by natural disturbances (Attiwill 1994). Given this, Daishowa-Marubeni International Ltd in northern Alberta, for example, foregoes harvest block size limits and green-up delays, leaves residual trees in clear cuts, and has extended stand rotation ages.

It is widely accepted, however, that human disturbances cannot truly replicate the patterns generated by natural disturbances, even if we had the requisite landscape modelling expertise.

We propose a fourth management paradigm - holistic management, or ecological landscape management (ELM) - as more suitable for landscape management. Similar to, yet subtlety different from, natural disturbance model management, this holistic approach would use natural disturbance patterns as a reference, not as processes to mimic. In ELM, natural disturbance patterns would help forest managers identify a forest management objective in the form of a target spatial structure, i.e., composition and configuration of forest conditions. Then, a management design would schedule interventions in strategic geographic locations so as to ensure that a landscape's structural state continued to be capable of maintaining all ecological processes as well as providing other desired values.

ELM, unlike NDM and forest zoning, is not a means to an end, but rather, focuses on the end, i.e., a forest objective. Also, unlike forest zoning management, ELM would not permanently divide a landscape into different forest uses and foreclose any future management options as our understanding of forest ecosystems improves.

With the ELM paradigm in place, we are left with the challenge of developing an effective modelling approach, i.e., a management design solution methodology.

\section{Modelling Approaches}

Forest management modelling involves four elements, regardless of specific approach:

1. A forest description, e.g., areas of stand types and age classes,

2. Management objectives and constraints, e.g., maximizing sustainable harvest flow while limiting maximum harvest opening size,

3. Forest performance indicators, e.g., measurements of forest growing stock and structure, and

4. Management strategy development, e.g., intervention application rules, amounts, timings and locations.

ELM, however, will require a spatial forest modelling approach, whereby all these modelling elements incorporate spatial structure (Baskent and Jordan 1995). That means that a forest would be described spatially with the geographical location of stands, as well as their condition. Further, management objectives, constraints and performance indicators would include some that involved the geographical configuration of forest conditions. Last, spatial management strategies would specify the geographical format of interventions; for example, harvest opening sizes, shapes, and proximity to other forest conditions. 
Simulation and mathematical optimization solution techniques have often been used successfully in contemporary forest management modelling. Some researchers have also tried to adapt them to spatial forest modelling with varying degrees of success. The following paragraphs elaborate.

The traditional simulation approach, as used in GISForman (Baskent and Jordan 1991) and Complan (Olympic Resource Management) for example, sequentially schedule management interventions, usually to achieve a single management objective. ELM, however, involves multiple and often conflicting spatial and aspatial forest objectives. These require a spatial forest modelling technique that is able to make compromises among objectives over an entire planning horizon. The simulation technique fails in this regard.

In contrast, optimization techniques based on mathematical programming, such as goal programming, can find solutions where multiple objectives exist, providing the problem is amenable to linear formulation. These techniques, however, suffer limitations when spatial objectives or constraints exist. As we introduce spatial constraints, such as maximum harvest opening size and adjacency delay, the problem size becomes overwhelming. As well, some non-linear objectives, such as maintenance of a desired patch size distribution, are inevitable in ELM.

In an effort to overcome these restrictions, some forest managers utilize a hierarchical-solution approach in developing spatially feasible management plans (Gunn 1991). The approach consists of three discrete phases: long-term aspatial planning (strategic), mid-term spatial planning (tactical) and short-term operational planning. At the strategic level, standlevel forest information is aggregated into relatively homogeneous strata that usually involve very coarse, or no, geographical detail. Strategic-level planning determines aspatial intervention schedules and maximum sustainable flows of various resources over a given planning horizon. These guide subsequent tactical level planning. At the tactical level, management interventions are scheduled in a spatially explicit manner. Commonly known as harvest block layout, this level of planning spatially aggregates forest stands into cut blocks, and assigns harvest sequences subject to resource flows and regulatory constraints such as harvest adjacency delay. At the operational planning level, tactical plan activities are detailed and scheduled by year or season.

Hierarchical planning thus enables a planner to gain a solution for the large and complex management planning problem by gradually increasing planning detail, geographical detail in particular. The approach has the added advantage that it determines the best possible set of interventions aspatially at the top level of planning and thereby helps assess the costs of considering various spatial constraints at subsequent planning levels. There is, however, the possibility that strategic level decisions are severed at the tactical level. For example, at the strategic level, a particular treatment regime (planting at period 1, spacing at period 3 followed by a clear cut at period 10) is attributed to a certain forest stratum consisting of a set of stands scattered across the landscape. At the tactical level, some or none of these stands may be included in any of the period 10 harvest blocks given their spatial location. Ignoring spatial detail at the strategic level, due to limitations of optimization techniques, precludes the use of a hierarchical planning in ELM where spatial structure, not resource flows, is a primary objective.

The foregoing discussion indicates that neither conventional simulation nor optimization techniques can solve the ELM design problem where structural forest objectives, such as spatial and temporal arrangement and distribution of forest conditions, exist. Some of these structural objectives do not lend themselves to linear formulation, and for others, finding a meaningful mathematical expression is exceedingly complex, even with overly simplified assumptions (Murray 1999, Nurullah et al. 1999).

As stands constitute basic units in spatial forest modelling, with each having potentially multiple treatment regimes, ELM design is a combinatorial problem (Murray 1999, Nurullah et al. 1999). Finding a solution to large combinatorial problems is similar to "finding a needle in a haystack." A particular class of algorithms, commonly labelled meta-heuristics, have been able to provide solutions in reasonable computational time, however (Lockwood and Moore 1993, Boston and Bettinger 1999). Essentially, a meta-heuristic is a hybrid search technique involving more than one algorithm, tailored to overcome certain traps, i.e., local optima, in an extremely large combinatorial solution space. These heuristics have the ability to formulate a problem using discretionary rules that would be difficult to formulate mathematically (Glover and Laguna 1997). In metaheuristic parlance an ELM design problem would be represented as either minimizing or maximizing an objective function subject to some constraints such as:

$$
\text { Minimize } E_{0}=\sum_{i=1}^{n} w_{i} F_{i}
$$

where

$E_{0}=$ the objective function value for the current treatment schedule,

$w_{\mathrm{i}}=$ the weighting coefficient that determines the relative importance of objective $I$, and

$F_{i}=$ the different penalty cost functions associated with $n$ number of individual management objectives such as control of timber flow, opening size, and patch size distribution.

The objective function typically involves several components, each expressed as a summation of numerical penalty function values. Penalty cost functions for each objective establish common non-monetary units and a mechanism for making trade-offs among different objectives. The objective function thereby accommodates different objectives measured in different units, e.g., timber in cubic metres and patch size distribution in hectares.

The meta-heuristic solution technique offers immense flexibility in solving ELM problems, since it is relatively easy to tailor and customize. For example, strategic and tactical level planning details can be fused. Therefore, spatially explicit management strategies can be developed to meet spatially explicit management objectives and constraints. Consequently, we see meta-heuristics, such as simulated annealing and tabu search, as a promising spatial forest modelling approach for the ELM problem.

The adoption of meta-heuristics is, however, far from straightforward. The technique requires careful programming and modelling. Here, the challenge is one of creating meta-heuristic solutions that accommodate evolving ELM requirements while still outperforming traditional modelling techniques. In fact, a poorly designed meta-heuristic implementation could prove ineffective in solving a large-scale ELM design problem. The 
success of a meta-heuristic implementation largely depends on the following elements: (i) good understanding and structuring of the problem; (ii) smart data structures and search algorithms to speed up computation time; (iii) generic and flexible design of objective functions and associated penalty cost functions, and (iv) a strategy to identify a good quality solution region in the search space.

Having identified a suitable ELM management paradigm and an appropriate meta-heuristic spatial forest modelling approach, our last task is identifying an appropriate software engineering technique for implementation.

\section{Software Engineering}

Most forest management modelling software in use today, e.g., SPECTRUM (USDA Forest Service), bear a legacy of traditional procedural programming languages like FORTRAN, Pascal or C. These languages work well within their design scope, but as program modifications and extensions are required to accommodate new functionality or behaviour, system designers and programmers find it enormously time-consuming, and in most cases end up scrapping the legacy code and redesigning the entire system from scratch (Rumbaugh et al. 1991).

These limitations suggest a more robust software engineering approach is needed. Software built using object-oriented (OO) engineering techniques seems to offer that advantage. Software so designed and developed includes individual components that are modularized and less interdependent, allowing internal mechanisms to be updated with greater ease than software designed and implemented with procedural approaches (He et al. 1999). The essence of the OO approach includes modularity (object identification), abstraction (object interaction), and encapsulation (object representation). These features would, for example, make OO-based spatial forest modelling components (a bundle of related objects) less interdependent (He et al. 1999). The OO approach also reduces effort in designing and programming by capitalizing on the commonality of model components, and models are more easily maintained, extended and updated. For example, in ELM an OO model would represent the spatial relationship of individual units such as cells, age cohorts, stands, harvest blocks, or habitat patches, as objects with common or specific behaviours that are easily used or extended.

We can expect the demand for new forest management modelling components to increase as our understanding of spatial forest landscape dynamics broadens and our commitment to landscape management strengthens. For that reason, the $\mathrm{OO}$ analysis and design approach is essential in robust model building for ELM.

\section{In Conclusion}

Given that scientific understanding of forest ecosystems and management design will frequently conflict with public knowledge and aspirations, we anticipate the need to continuously adjust management approaches in the future. We believe that our ELM management paradigm, coupled with a meta-heuristic modelling approach implemented with object-oriented software engineering provides enough flexibility to accommodate formulation and implementation of various management policies and objectives in different decision-making environments. Nonetheless, we feel that other management paradigms or modelling techniques should not be dismissed in pursuing forest landscape management. In fact, variety is desirable if for- est management is to successfully evolve with changing societal values and improved understanding of forest ecosystems Success in forest landscape management design will not rest solely on establishing a design framework like the one proposed in this paper. Forestry professionals must be open and proactive as forest ecosystem science advances. As a start, they should assume leadership in designing management that functionally links interventions to forest objectives and the values they generate, rather than blindly implementing regulatory statutes.

\section{References}

Attiwill, P.M. 1994. The disturbance of forest ecosystems: the ecological basis for conservation management. Forest Ecology and Management, 63: 247-300.

Baskent, E.Z. and G.A. Jordan. 1991. Spatial wood supply simulation modelling. For. Chron. 67(6): 610-621.

Baskent, E.Z. and G.A. Jordan. 1995. Designing forest management to control spatial structure of landscapes. Landscape and Urban Planning 34: 55-74.

Baskerville, G.L. 1997. Another good idea. In Proceedings ELM Workshop, October 6-7, 1997, Fredericton, NB. pp. 21-24.

Bergeron, Y., B. Harvey, A. Leduc and S. Gauhier. 1999. Forest management guidelines based on natural disturbance dynamics: Stand and forest-level considerations. For. Chron. 75(1): 49-54.

Binkley, C.S. 1997. Preserving nature through intensive plantation management: The case for forestland allocation with illustrations from British Columbia. For. Chron. (73(5): 553-559.

Booth, D.L., D.W.K. Boulter, D.J. Neave, A.A. Rotherham and D.A. Welsh. 1993. Natural forest landscape management: A strategy for Canada. For. Chron. 69(2): 141-145.

Boston, K. and P. Bettinger. 1999. An analysis of Monte Carlo integer programming, Simulated Annealing, and Tabu Search heuristics for solving spatial harvest scheduling problems. For. Sci. 45(2): 292-301.

Brooks, D.J. and G.E. Grant. 1992. New perspectives in forest management: background, science issues, and research agenda. USDA FS. PNW-RP-456. $17 \mathrm{p}$.

Franklin, J.F. 1998. The natural, the clear-cut, and the future. Northwest Science, (72)2: 134-138.

Glover, F. and M. Laguna, 1997. Tabu Search. Kluwer Academic Publishers, Massachusetts, USA. 382 p.

Gunn, E.G. 1991. Some aspects of hierarchical production planning in forest management. In Proceedings of the 1991 Symposium on Systems Analysis in Forest Resources. March 3-6 1991, South Carolina. pp. 54-62. USDA GTR SE-74.

He, H.S., D.J. Mladenoff and J. Boeder. 1999. An object-oriented forest landscape model and its representation of tree species. Ecological Modeling 119: 1-19.

Kimmins, J.P. 1993. Ecology, environmentalism and green religion. For. Chron. 69(3): 285-289.

Lockwood, C.G. and T.G.E. Moore. 1993. Harvest scheduling with spatial constraints: simulated annealing approach. Can. J. For. Res. 23: 468-478.

Murray, A.T. 1999. Spatial restrictions in harvest scheduling. For. Sci. 45(1): 45-52.

Nurullah, A.M.M., G.A. Jordan and E.Z. Baskent. 2000. Spatial stratification in forest modelling. For. Chron. 76(2): 311-317.

Oliver, C.D. 1999. The future of the forest management industry: Highly mechanized plantations and reserves or a knowledge-intensive integrated approach? For. Chron. 75(2): 229-245.

Rumbaugh, J., M. Blaha, W. Premerlani, F. Eddy and W. Lorensen. 1991. Object-orientated modeling and design. PrenticeHall, New York. 500 p.

Seymour, R.R. and M.L. Hunter. 1992. New forestry in Eastern SpruceFir forests. Maine Agricultural Experiment Station, University of Main. $716 \mathrm{p}$.

Sherry, E.E. and C.J. Johston. 1999. The forgotten forest: Revisiting the forestland allocation strategy. For. Chron. 75(6): 919-929. 